\title{
DETERMINATION OF ADRENALINE AND NORADRENALINE BY RESONANCE RAMAN SPECTROMETRY
}

\author{
Mohammed S. Rahaman* and Micilael D. Morris \\ Department of Chemistry, University of Michigan, Ann Arbor, MI 48104, U.S.A.
}

(Received 25 February 1975. Accepted 25 March 1975)

Conventionally, determination of adrenaline and noradrenaline in urine and other matrices is carried out by fluorimetry after conversion of the catecholamines into the trihydroxyindoles. ${ }^{1,2}$ The method suffers from certain disadvantages. First, as with other fluorimetric methods, it is susceptible to interference from a variety of quenching agents. Second, many pharmaceuticals give fluorescent products, which may interfere. Finally, adrenaline and noradrenaline are not differentiated by the procedure. However, adrenaline alone will undergo the initial oxidation in acidic solution, so noradrenaline can be determined by difference.

In the past few years, resonance Raman spectrometry has emerged as a sensitive and selective probe for many molecules of biological interest. ${ }^{3}$ Most workers have confined their studies to molecules which themselves can show resonance-enhanced Raman spectra. A few attempts to prepare derivatives suitable for resonance Raman spectrometry have been reported. ${ }^{4,5}$

Moreover, the potential of resonance Raman appears to have been largely overlooked by analytical chemists, although the technique is simple, offers high resolution and freedom from the quenching effects which plague fluorescence. ${ }^{6}$ The principal drawback of resonance Raman spectrometry is the fact that conventional spectrometers cannot distinguish between Raman scattering and fluorescence. With the advent of convenient instrumentation for fluorescence-rejecting techniques such as coherent anti-Stokes scattering, ${ }^{7,8}$ inverse Raman spectrometry, ${ }^{9}$ and timeresolved Raman spectrometry ${ }^{10,11}$ the fluorescence problem appears tractable.

In the present communication we report the application of resonance Raman spectrometry to the determination of adrenaline and noradrenaline as the aminochromes. Aerial. oxidation of these molecules, catalysed by copper(II), is well known. ${ }^{12}$ The technique is simple, applicable to concentrations as low as $1 \times 10^{-6} \mathrm{M}$ and allows determination of adrenaline and noradrenaline on a single sample.

\section{EXPERIMENTAL}

Apparatus

A Spex 1401 double monochromator, a cooled RCA C31034A photomultiplier and both d.c. and photon-counting detection systems were used for these experiments. Slitwidths of $400 \mu \mathrm{m}\left(9 \mathrm{~cm}^{-1}\right)$ were employed. Scan-rates of $20-50 \mathrm{~cm}^{-1} / \mathrm{min}$ were used. The excitation source was a Coherent Radiation CR-5 argon-ion laser. Melting point capillaries were used as sample containers, with conventional transverse excitation and observation at $90^{\circ}$ to the incident radiation. Absorption spectra were obtained with a Cary 14 spectrophotometer.

* Present address: Department of Chem. \& Chem. Eng. Michigan Technological University, Houghton, Michigan 49931 .

\section{Reagents}

Adrenaline hydrogen tartrate and noradrenaline hydrogen tartrate were obtained from the Sigma Chemical Company and used as received. Stock solutions of these reagents were stored under refrigeration and replaced at frequent intervals. All other reagents were of ACS reagent grade.

\section{Procedure}

The aminochromes were prepared by addition to the catecholamines of stock copper(II) sulphate, ammonium chloride and potassium nitrate solutions to make the solutions $0.01 M$ in cupric ion, $0.04 M$ in ammonium ion, and $0.05 M$ in nitrate. The $\mathrm{pH}$ of the resulting solution was adjusted to 5 with ammonia. Raman scattering intensity was measured at $1480 \mathrm{~cm}^{-1}$ (adrenaline) and $1430 \mathrm{~cm}^{-1}$ (noradrenaline), the nitrate $1050-\mathrm{cm}^{-1}$ line being used as an internal standard. $\mathrm{Ar}^{+} 496.5-\mathrm{nm}$ excitation is optimum, but $\mathrm{Ar}^{+} 488.0 \mathrm{~nm}$ may be used.

\section{RESULTS AND DISCUSSION}

Absorption spectra of the aminochromes formed are shown in Fig. 1. The compounds have similar spectra, but the adrenaline product shows higher absorption. In the absence of ammonium ion similar spectra were observed, but with lower intensities, implying incomplete oxidation.

The resonance Raman spectra of the adrenaline and noradrenaline aminochromes are presented in Fig. 2. In addition to these bands, weaker bands occur around 1680 , 1625,1100 and $500 \mathrm{~cm}^{-1}$. The two bands of the adrenaline species at 1480 and $1465 \mathrm{~cm}^{-1}$ and the single band of noradrenaline at $1430 \mathrm{~cm}^{-1}$ allow ready differentiation of these compounds. Interpretation of these spectra is in progress and will be reported at a later date.

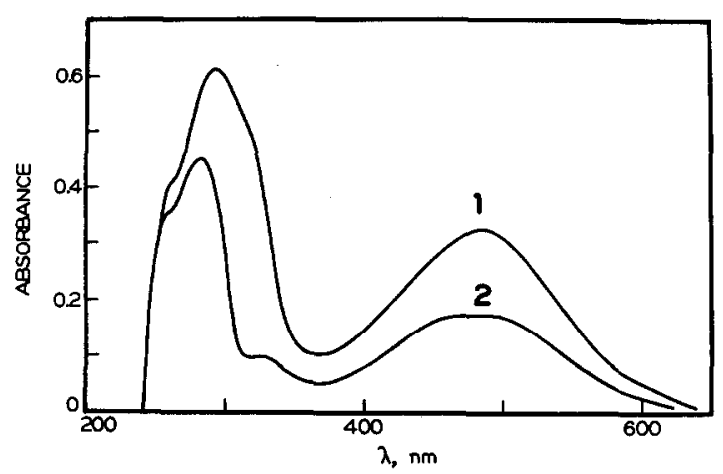

Fig. 1. Absorption spectra of aminochrome systems, $\mathrm{pH}=5 . \quad 1-1 \times 10^{-4} M \quad$ adrenaline; $2-1 \times 10^{-4} M$ noradrenaline. 


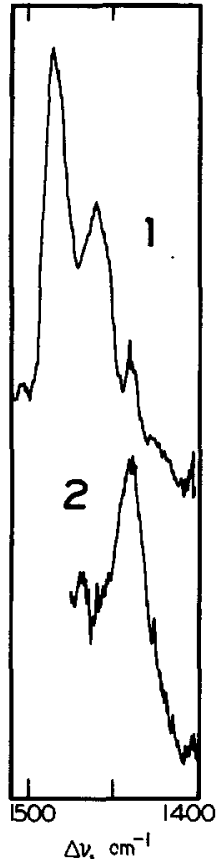

Fig. 2. Resonance Raman spectra of aminochromes, $\lambda_{\mathrm{e}}=$ $496.5 \mathrm{~nm} . \quad 1-1 \times 10^{-5} \mathrm{M}$ adrenaline; $2-1 \times 10^{-5} \mathrm{M}$ noradrenaline.

Table 1 shows analytical data for these solutions. The working curve is linear over the range $5 \times 10^{-6}-2 \times$ $10^{-4} \mathrm{M}$. Above the $10^{-5} \mathrm{M}$ level, the precision of the measurements is about $\pm 3 \%$. Although signals are detectable down to about the $10^{-6} \mathrm{M}$ level, the noise in our system is too great to allow analytical use of the signals below about $5 \times 10^{-6} \mathrm{M}$. More sophisticated signal conditioning could probably lower the detection limits and the limit of the useful concentration range.

Our current studies have been limited to synthetic solutions. We have carried out some preliminary experiments on urine matrices. Prior concentration of the catecholamines by the conventional technique of adsorption on alumina and elution with acid ${ }^{1}$ is necessary to bring the conecntrations to a usablc level. This step also serves to remove fluorescent substances from the sample. Our results
Table 1. Concentration dependence of aminochrome resonance Raman scattering

\begin{tabular}{cccc}
\hline \multicolumn{2}{c}{ Adrenaline } & \multicolumn{2}{c}{ Noradrenaline } \\
$C, 10^{-5} M$ & $I_{\text {sample }} / I_{\mathrm{NO}_{3}^{-}}$ & $C, 10^{-5} M$ & $I_{\text {sample }} / I_{\mathrm{NO}_{3}^{-}}$ \\
\hline 0.45 & 0.032 & 0.55 & 0.025 \\
1.05 & 0.082 & 1.00 & 0.045 \\
1.60 & 0.122 & 4.0 & 0.140 \\
2.03 & 0.158 & 6.0 & 0.205 \\
3.00 & 0.230 & 7.5 & 0.260 \\
6.0 & $0.47_{5}$ & 9.0 & $0.30_{5}$ \\
7.0 & $0.56_{0}$ & 10.0 & $0.35_{2}$ \\
8.0 & $0.64_{2}$ & & \\
10.0 & $0.80_{5}$ & & \\
\hline
\end{tabular}

show that adrenaline and noradrenaline from urine samples are detectable by this technique. Studies of various clinical specimens are now in progress to determine the relative merits of the resonance Raman and fluorimetric approaches to catecholamine determination.

\section{REFERENCES}

1. P. L. Wolf, D. Williams, T. Tsudaka and L. Acosta, Methods and Techniques in Clinical Chemistry, pp. 107113. Wiley-Interscience, New York, 1972.

2. J. A. Lorraine and E. T. Bell, Hormone Assays and Their Clinical Application, 3rd Ed., pp. 251-287. Livingstone, Edinburgh, 1971.

3. T. G. Spiro, Acct. Chem. Res., 1974, 7, 339

4. P. R. Carey, A. Froese and H. Schneider, Biochemistry, 1973, 12, 2198.

5. P. R. Carey and H. Schneider, Biochem. Biophys. Research. Commun., 1974, 57, 831.

6. C.-W. Tsai and M. D. Morris, Anal. Chim. Acta, in the press.

7. R. F. Begley, A. B. Harvey, R. L. Byer and B. S. Hudson, J. Chem. Phys., 1974, 61, 2466.

8. R. F. Begley, A. B. Harvey and R. L. Byer, Appl. Phys. Lett., 1974, 25. 387.

9. E. Yeung, J. Mol. Spectry., 1974, 53. 379.

10. R. P. VanDuyne, D. L. Jeanmaire and D. F. Shriver, Anal. Chem., 1974, 46, 213.

11. F. E. Lytle and M. S. Kelsey, ibid., 1974, 46, 855.

12. R. A. Heacock, Advan. Heterocyclic Chem., 1965, 5 , 205.

Summary-Aminochromes of adrenaline and noradrenaline show resonance Raman scattering at 1480 and $1430 \mathrm{~cm}^{-1}$ respectively, with $\mathrm{Ar}^{+}$excitation. Scattering intensity is a linear function of concentration. Detection limits are $1 \times 10^{-6} M$. Both catecholamines can be determined in a single measurement. 